\title{
Research on the Direction of China's Energy Development and Coping Strategies Based on the Trend of World Energy Development
}

\author{
Lixin Zhang, Ye Tao, Yan Jiang, and Ju Ma \\ School of Management, Qingdao University Of Technology, Qingdao, Shandong266520, China
}

\begin{abstract}
To realize the modernization of the national economy, it is necessary to develop energy science and technology for China,which is third largest countries in the world.The rapid development of science and technology has promoted the continuous transformation of the global energy industry. By analyzing the trend of energy development in the world today, this paper discusses the challenges that the global energy development facing and the situation and tasks faced by China's energy sustainable development, and looks forward to China's strategies to cope with the development of the world's energy.
\end{abstract}

\section{Introduction}

Energy science and technology is an important development strategy that is closely watched by all countries in the world today. It covers a wide range of areas and has a large impact. The world is now undergoing a new round of information revolution. Whoever seizes the opportunity will be able to become a superpower. The global production organization model and lifestyle are undergoing fundamental changes.There is an urgent need to give a clear answer that in the face of the challenge of the information revolution, what kind of strategies should be adopted by energy science and technology to adapt and support the development of the energy industry.

At present, the development of the world's energy science and technology is becoming a trend, and the old energy sources are drying up. There is an urgent need for science and technology to inject new energy into new energy sources. However, the world's energy development trends are facing many problems and challenges. In response to this situation, how should China adapt itself to the new situation in combination with its own level of development? The development of new energy has been an important development strategy at present.

\section{Major issues and challenges facing the current global energy development strategy}

On March 31, 2017, BP China released the 2017 World Energy Outlook, which assesses the long-term development trends of energy sources in the world and regions, and forecasts the development of the world energy market in the next 20 years. The BP report pointed out that by 2035 , oil, natural gas and coal will still be the dominant energy of the world economy, accounting for more than $75 \%$ of the total energy supply in 2035 , and the growth rate of natural gas will exceed that of petroleum and coal by 2035. The share of primary energy will exceed coal and become the second largest source of fuel. [1]

The following characteristics can be drawn based on the analysis of BP energy outlook:

\subsection{Global total energy demand continues to grow slowly}

BP's "World Energy Outlook (2017 Edition)" predicts that the global energy demand from 2015 to 2035 is expected to increase by $30 \%$, with an average annual increase of $1.3 \%$. This increase in energy demand is significantly lower than the expected growth rate of $3.4 \%$ per year in global GDP, reflecting the improvement in energy efficiency due to technological progress and environmental concerns. The growth of the world economy requires more energy, although the degree of its growth is tempered by the reduction of energy intensity (energy per unit of GDP): the global GDP has doubled and the energy demand has only increased by $30 \%$.

Due to the rebalancing of the Chinese economy and the global emphasis on improving energy efficiency, the global energy intensity decline rate is expected to accelerate. China will be the largest energy growth market, although it may be overtaken by India at the end of the horizon.

\subsection{The development of energy supply towards multi-polarization}

"Corresponding author email: 2498566339@qq.com 
According to BP statistics, the growth rate of primary energy consumption in the world in 2012, 2013, 2014 and 2015 was $1.4 \%, 2.0 \%, 1.1 \%$ and $1.0 \%$ respectively, which was significantly lower than the average annual growth rate of $2.7 \%$ in the previous 10 years. [2] The shale oil and gas revolution has led to major changes in the structure of the world's energy region. For example, the phenomenon of "production shifting westward and consumption moving eastward" appears in the oil field. Non-OPEC countries such as Russia and the United States have gradually exceeded their OPEC oil production. [3] With the rise of unconventional oil and gas such as shale oil and shale gas, the energy supply is increasingly polarized and diversified. Driven by the growth of LNG in the United States, shale gas production accounts for two-thirds of the increase in natural gas supply. Due to increased supply in Australia and the United States, LNG growth is expected to lead to the formation of a globally integrated natural gas market based on US gas prices.

As a cleaner source of energy, renewable energy plays an increasingly important role in the diversified development of energy supply. [4]Driven by the increasing competitiveness of solar and wind power, the growth of renewable energy will quadruple. In the next 20 years, China will be the largest source of renewable energy growth, and its incremental renewable energy will exceed the sum of the EU and the United States. In summary, the development of energy supply in the direction of diversification is a general trend.

\subsection{Certain measures still need to be taken to reduce carbon emissions}

The goal set by the Paris Climate Change Conference is to keep the global average temperature within $2^{\circ} \mathrm{C}$ above the pre-industrial level and work hard to keep the temperature within $1.5^{\circ} \mathrm{C}$. To achieve the temperature rise control target of $1.5^{\circ} \mathrm{C}$, in 2040 , zero emissions will be achieved in 2040 . However, the effect of greenhouse gas emission reduction comes from cooperation and common emission reduction. [5]

BP estimates that carbon emissions are expected to increase at a rate of less than one-third of the past two decades, with an average annual growth rate of $0.6 \%$, and an average annual growth rate of $2.1 \%$ over the past two decades, reflecting energy efficiency and fuel structure are constantly changing. If this goal is achieved, it will be the lowest emission growth rate in any one of the two decades since it was recorded in 1965. However, it is expected that during this period, carbon emissions from energy use will still increase by about $13 \%$ under the basic scenario. This far exceeds the forecast of the International Energy Agency (IEA) 450 scenario - that by 2035 carbon emissions need to drop by about $30 \%$ before they have the opportunity to achieve the goals of the Paris Climate Agreement. BP's forecast of global carbon emissions growth is shown in Figure 1.

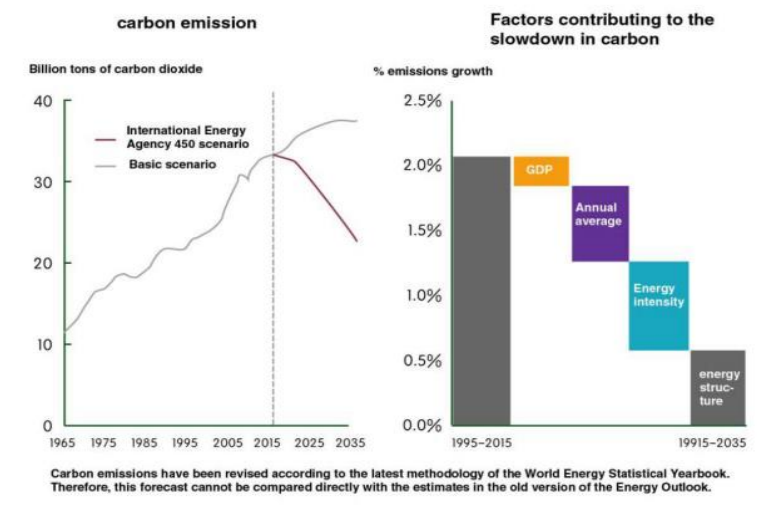

Fig. 1 Forecast of global carbon emissions growth over the next 20 years Source: BP p.l.c. 2017

Therefore, global energy-related carbon emissions will peak around 2030 .

\subsection{The future energy consumption structure is still dominated by fossil energy}

BP predicts that non fossil fuels will account for half of the growth of energy supply in the next twenty years, but oil, gas and coal will remain the main source of energy for the world economy, accounting for more than $75 \%$ of the total energy supply in 2035 , compared with $85 \%$ in 2015.BP's forecast of global primary energy consumption and share is shown in Figure 2.
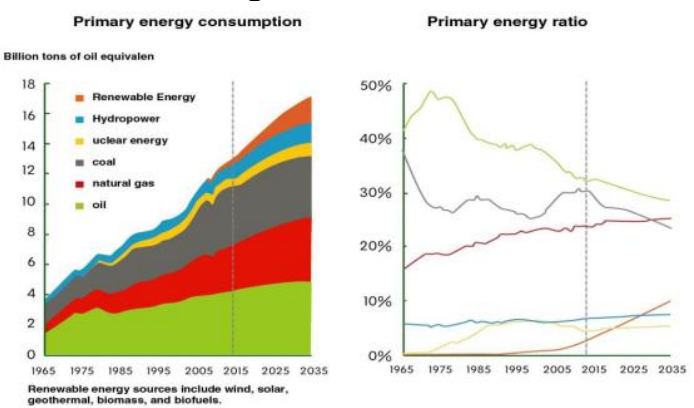

Fig. 2 Forecast of world primary energy consumption and proportion in 2035 Source: BP p.1.c. 2017

Although oil demand is expected to slow gradually during the horizon, it will still grow at an average annual rate of $0.7 \%$. The transportation sector continues to consume most of the world's oil, and its share of global demand is still close to $60 \%$ in 2035 . However, by the early 1930s, the non-fuel use of petroleum, especially for the production of petrochemicals, would be the main source of oil demand growth. As China turns to cleaner, lower-carbon fuels, coal consumption is expected to peak by the mid-2020s. India is the largest growth market for coal demand. Its share of world coal demand has doubled from about $10 \%$ in 2015 to $20 \%$ in 2035 . [2]

Although there is a certain difference in forecast, as long as countries take certain measures to solve the problem of climate change, the trend of energy structure changes in the future is about the same, and fossil fuels will still dominate the energy composition.

\subsection{Natural gas is increasingly emerging}

Thanks to energy policies that encourage industry and 
power generation to transform, coal's share continues to shrink and shift to natural gas. The main growth comes from China, the Middle East and the United States.

According to the BP report, the net increase in global LNG exports (2.1 billion cubic meters) is from Australia (19 billion cubic meters). The LNG exports of the United States increased from 700 million cubic meters in 2015 to 4.4 billion cubic meters in 2016. [6]

Finally, BP predicts that by 2035 China will account for $26 \%$ of the world's total energy consumption and $35 \%$ of global net growth. With the continuous evolution of China's energy structure, China's energy intensity will decline by $45 \%$ in the horizon, with an annual decline of $3 \%$. BP's forecast of global gas supply growth and some of its consumption are shown in Figure 3.
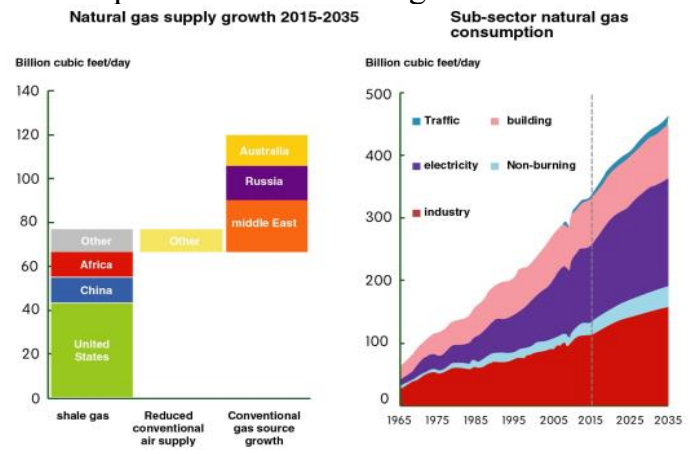

Fig. 3 Forecast of global gas supply growth and partial consumption 2015-2035 Source: BP p.1.c.2017

\subsection{Transfer of energy trade centers to non-OECD countries}

In terms of energy trade, BP issued its own prediction that the global energy demand of non-OECD countries will increase significantly by 2040 .

According to BP's forecast, by 2035 Asia will account for nearly $80 \%$ of the net imports between regions, and more than $40 \%$ of primary energy demand will depend on imports, which will basically contribute to all new energy trade. According to the prediction of China Energy Research Association, China's foreign oil dependence in 2030 will reach around 68\%. [7]

\section{China's main countermeasures in the face of global energy development strategy}

(1) Energetically develop energy science and technology, and follow the energy development path in line with China's national conditions. Currently, world-wide energy is dominated by high-quality oil and gas, and China is still dominated by coal. From the perspective of the energy structure of all countries in the world, all industrialized countries use oil-vapor fuels as their mainstay. This is a choice to increase energy efficiency, reduce energy system costs, reduce environmental pollution, and provide quality services. It is also a basic trend of energy development in the world today. However,resources are rich in coal and poor in oil in China, and economically underdeveloped,so China is continue to be one of the countries in the world with a coal-based energy structure for quite some time. Therefore, there is an urgent need for energy science and technology innovation.

(2) Build a global energy internet. The global energy internet is a global energy allocation platform that uses UHV grids as backbone grids and smart grids to deliver clean energy. [8] The core idea of the global energy Internet construction is clean development, the use of clean energy such as wind, light, and water to replace fossil energy for power generation, and UHV transmission technology is used to connect these clean electricity through various regions, countries, and continents. The power grid is delivered to millions of households in a safer, more reliable and more economical way. The two alternative is to transform energy structure from fossil energy to clean energy and to implement electric energy substitution on energy consumption.

(3) Encourage environmental protection. Globally, fossil energy sources emit large amounts of pollutants every year, which not only cause serious pollution and damage to the atmosphere, water quality, soil, etc., but also cause great changes to the climate. The replacement of fossil energy with clean energy will effectively reduce the discharge of various pollutants. Promote ecological restoration and environmental protection.

(4) Promote economic recovery. Globalization is not only conducive to the upgrading of energy structure, the promotion of industrial restructuring, the development of upstream and downstream industries, and the promotion of the development of green industries; it can drive infrastructure construction and greatly increase employment; it can also promote the optimal allocation of energy elements for development. Provide new power to provide a new engine for economic growth; it can also promote the development and utilization of renewable energy, turn resource advantages into economic advantages, and promote the country's accelerated development.

(5) Making full use of the leading role of strategic planning. We should actively respond to the call of the times, further strengthen ideological awareness,and integrate the global energy concept of green, low-carbon, interconnected, and jointly built and shared energy into China's energy development strategy. Strengthen the top-level design, scientifically plan global energy development, guide and promote the development of various types of clean energy, and promote the close integration of power planning in various countries with global energy planning.

(6) Giving full play to the supporting role of innovation driven. We will focus on promoting breakthroughs in key technologies, equipment development, and standards construction, and comprehensively improve the safety, economics, and reliability of global energy development. At present, China has made breakthroughs in UHV, smart grid, clean energy, and operation control of large power grids.

\section{Conclusion}


China is a country of economy and population. To realize the modernization of the national economy, energy is the foundation. Only ensuring the sustainable development of the energy industry can promote the sustainable development of the Chinese economy. Strengthening and developing energy science and technology is the key to ensure China is transiting to a high-quality, high-efficiency, low-consumption country with environmentally-friendly energy system. China's energy science and technology is in its infancy and it has a long way to go. We should strongly encourage the development of new theories and technologies and make a contribution to the revitalization of China's energy industry.

\section{References}

1. BP. World Energy Outlook (2017 Edition) [R/0 L]

2. BP. World Energy Outlook (2016 Edition) $[\mathrm{R} / 0 \mathrm{~L}]$

3. Wang Lu. Analysis of Energy Development Trends at Home and Abroad [J]. Modern Economic Information, 2017(14): 297-300.

4. Kaveri K. Iychettira,Rudi A. Hakvoort,Pedro Linares,Rob de Jeu. Towards a comprehensive policy for electricity from renewable energy: Designing for social welfare[J]. Applied Energy,2017,187.

5. Shi Dan. China's lead in energy transformation, risk evolution and response ideas [J]. China Energy, 2017, 39(11):19-23+13.

6. Jiang Tianhai. Global Energy Market: Slowing Consumption Accelerating Transformation [J]. Science News, 2017(06):20-21.

7. Qiu Lijing. Prospects for global energy development trends from 2030 to 2040[J]. New Energy Economics and Trade Review, 2017(05):36-41.

8. Cheng Zhiqiang. China's Wisdom to Promote World Energy Transformation and Development [J]. Wisdom China, 2017(07):10-12. 